\title{
STUDY OF PULMONARY FUNCTION TEST IN ALLERGIC RHINITIS PATIENTS OF SULLIA, DAKSHINA KANNADA
}

\author{
Anand K. S. S1, Ravi G. N², K. N. Narasimhaswamy3
}

${ }_{1}^{1}$ Assistant Professor, Department of Physiology, AIMS, B. G. Nagara.

${ }^{2}$ Assistant Professor, Department of Physiology, AIMS, B. G. Nagara.

3 Professor and HOD, Department of Physiology, AIMS, B. G. Nagara.

\begin{abstract}
\section{BACKGROUND}

Allergic rhinitis is a very common disease with immense social impact. It is characterised by paroxysms of sneezing, rhinorrhoea, nasal obstruction and itching of the eyes, nose and palate. It is also frequently associated with altered pulmonary function. Present study intends to study changes in pulmonary function in patients of allergic rhinitis.
\end{abstract}

AIM

The present study was done to evaluate changes in pulmonary functions in patients of allergic rhinitis.

\section{MATERIALS AND METHODS}

30 patients of allergic rhinitis who met the inclusion criteria formed the study group, while age sex-matched 30 individuals formed control group. On both groups, after taking informed consent pulmonary function test was performed. Data was tabulated and analysed for statistical significance by Mann-Whitney $U$ test and student's ' $t$ ' test.

\section{SETTINGS AND DESIGN}

The present study was a comparative study consisting of 60 (30 cases and 30 controls) in the age group of 18-45 years age.

\section{RESULTS}

The $\mathrm{p}$ value of MVV was found to be highly significant indicating marked diminution of MVV in study group as compared to the control. The p value of FEV1 was observed to be mildly significant showing mild decrease in FEV1 in study group. The $p$ value of FEV $1 \%$ was of very high significance indicating a marked decrease in FEV 1\% in the study group. The p value of PEFR is highly significant showing marked diminution of PEFR in the study group.

\section{CONCLUSIONS}

Change in pulmonary functions was measured using PFT in patients of allergic rhinitis of Sullia. It was observed that PFT parameters like FEV1, FEV 1\%, PEFR, MVV showed a definite and significant decrease in patients as compared to controls.

\section{KEYWORDS}

Allergic Rhinitis, Pulmonary Function Tests.

HOW TO CITE THIS ARTICLE: Anand KSS, Ravi GN, Narasimhaswamy KN. Study of pulmonary function test in allergic rhinitis patients of Sullia, Dakshina Kannada. J. Evolution Med. Dent. Sci. 2016;5(79):5867-5869, DOI: 10.14260/jemds/2016/1323

\section{INTRODUCTION}

The major types of pulmonary function tests include measurement of lung volume using spirometry and quantization of diffusing capacity. Measurements of maximal respiratory pressures and flow volume loops, which record forced inspiratory and expiratory flow rates are also useful in specific clinical circumstances.

The Slow Vital Capacity (SVC) can also be measured with spirometers, which collect data for at least 30 seconds. The SVC may be a useful measurement when the Forced Vital Capacity (FVC) is reduced and airways obstruction is present.

Financial or Other, Competing Interest: None.

Submission 17-08-2016, Peer Review 20-09-2016,

Acceptance 26-09-2016, Published 30-09-2016.

Corresponding Author:

Dr. Anand K. S. S,

Assistant Professor,

Department of Physiology,

AIMS, B. G. Nagara-571448.

E-mail: puttachianand@gmail.com

DOI: $10.14260 /$ jemds/2016/1323
Slow exhalation results in a lesser degree of airway narrowing and frequently the patient can exhale a larger, even normal volume. In contrast the vital capacity with restrictive disease is reduced during both slow and fast manoeuvers. Thus, if the slow or forced vital capacity is within the normal range, a significant restrictive disorder is virtually excluded and it is generally unnecessary to measure static lung volumes (Residual volume and total lung capacity).(1)

Rhinitis is common, affecting nearly everyone at one time or another. Many cases can be classified into a specific syndrome, each with its own causes and treatments. These syndromes are recognised mainly by patterns of symptoms and to a lesser extent physical signs.

Rhinitis is defined as the occurrence of annoying nasal symptoms including discharge, itching, sneezing, congestion and pressure.

Allergic rhinitis, one of the rhinitis syndromes, is associated with a symptom complex characterised by paroxysms of sneezing, rhinorrhoea, nasal obstruction and itching of the eyes, nose and palate. It is also frequently associated with postnasal drip, cough, irritability and fatigue.(2) 
Seasonal allergic rhinitis refers to allergic rhinitis symptoms that typically occur at a particular time of the year. Perennial allergic rhinitis refers to allergic rhinitis symptoms that occur year round.

It is disease with high prevalence and morbidity. Allergic rhinitis appears to be exceedingly common. It is believed to affect upto 40 percent of children and 10 to 30 percent of adults. The prevalence in the industrialised world is increasing, particularly in urban areas.(3)

Allergic rhinitis is also associated with significant morbidity and expenses. It accounts for at least 2.5 percent of all patient's visits, 2 million lost school days per year, 6 million lost work days and 28 million restricted work days per year. Pulmonary function tests are altered in these patients of allergic rhinitis.

Evaluation of pulmonary function is important in many clinical situations, both when the patient has a history or symptoms suggestive of lung disease and when risk factors for lung disease are present. The major types of pulmonary function tests include spirometry, measurement of lung volume and quantitation of diffusing capacity. Measurements of maximal respiratory pressures and flow volume loops, which record forced inspiratory and expiratory flow rates are also useful in specific clinical circumstances.

Many diseases being slow and insidious finally manifest themselves with the non-specific symptom of dyspnoea on exertion. Pulmonary function tests are an essential part of the workup of such patients. In the outpatient setting in which several days to weeks are available to make the diagnosis, a cost efficient method of ordering pulmonary function tests is to start with spirometry and then order further tests in a stepwise fashion to refine the diagnosis. ${ }^{(4)}$

\section{METHODOLOGY}

The present study was undertaken to study the effect of allergic rhinitis on PFT in Sullia population. A total of 60 subjects in the age groups of 18 to 45 years were recruited; 30 subjects were patients of allergic rhinitis; 30 male subjects of the same age group were taken as a control group from among the attenders and technicians of the KVG Medical College and Hospital staff, Sullia. Subjects with any cardiorespiratory illness like hypertension, bronchial asthma, obesity and tuberculosis or any other drug dependency, smoking, alcohol, tobacco chewing were excluded for the study. Only male subjects in the age group between 18-45 years were included for the study.

The method of study considered was of taking a detailed personal history of subjects with detailed questionnaire on allergic rhinitis. For eliciting any respiratory symptoms, Medical Research Council modified questionnaire was used. Anthropometry and clinical examination was done for all the subjects.

\section{Anthropometric Parameters}

Age (in year), height (in $\mathrm{cm}$ ), weight (in $\mathrm{kg}$ ) and body mass index was calculated using the formula $\mathrm{Wt}$ in $\mathrm{Kg} / \mathrm{Ht}^{2}$ in meters.

\section{Clinical Examination}

A detailed clinical examination of respiratory system was done.

The subjects were made familiar with the working of instrument. The protocol of the tests was explained in brief. All tests were conducted after the subjects were made to sit comfortably in a chair for 15 minutes and the pulmonary function tests were done for all the subjects in the morning between 10 am to 12 noon in the Pulmonary Function Laboratory at KVG Medical College and Hospital, Sullia. The pulmonary function test was done using a computerised vitalograph - version 4.02 (model of Spirometer) under standard conditions. FEV1, FEV 1\%, PEFR, MVV was recorded.

\section{Statistical Analysis}

Descriptive statistical analysis has been carried out in the present study. Results on continuous measurement were presented on mean $\pm \mathrm{SD}$ and results on categorical measurements were presented in number (\%). Statistical significance was assessed at 5\% level. Student's " $t$ " test (two tailed and independent) has been used to find significance of study parameters between two groups, Mann-Whitney U test has been used to find the significance of FEV $1 \%$.

\section{RESULTS}

\begin{tabular}{|c|c|c|c|c|}
\hline \multirow{2}{*}{ Age in Year } & \multicolumn{2}{|c|}{ Control Group } & \multicolumn{2}{c|}{ Study Group } \\
\cline { 2 - 5 } & Number & $\mathbf{\%}$ & Number & $\mathbf{\%}$ \\
\hline Up to 30 & 15 & 50.0 & 13 & 43.3 \\
\hline $31-40$ & 7 & 23.3 & 11 & 36.7 \\
\hline $41-45$ & 3 & 10.0 & 6 & 20.0 \\
\hline Total & $\mathbf{3 0}$ & $\mathbf{1 0 0 . 0}$ & $\mathbf{3 0}$ & $\mathbf{1 0 0}$ \\
\hline Table 1: Age Distribution of Two Study Groups \\
\hline
\end{tabular}

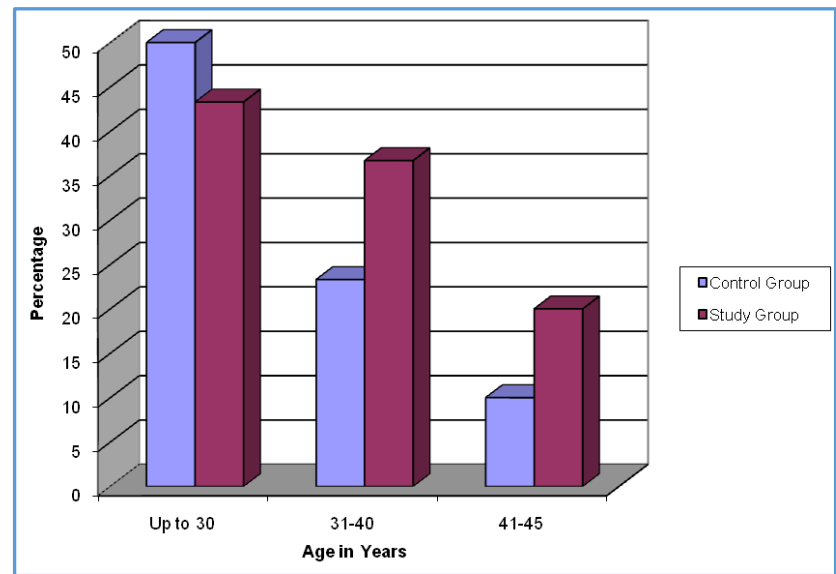

\begin{tabular}{|c|c|c|c|}
\hline $\begin{array}{l}\text { Pulmonary } \\
\text { Function } \\
\text { Test }\end{array}$ & $\begin{array}{c}\text { Control } \\
\text { Group }\end{array}$ & $\begin{array}{l}\text { Study } \\
\text { Group }\end{array}$ & $\begin{array}{c}\mathbf{P} \\
\text { Value }\end{array}$ \\
\hline $\begin{array}{c}\text { Maximum } \\
\text { ventilatory } \\
\text { volume } \\
\text { (MVV) }\end{array}$ & $111.62 \pm 28.21$ & $92.53 \pm 26.76$ & $\begin{array}{c}0.009 \\
t=2.689\end{array}$ \\
\hline $\begin{array}{c}\text { Forced } \\
\text { Expiratory } \\
\text { Volume in } \\
1 \mathrm{sec} \\
\text { (FEV1) }\end{array}$ & $2.92 \pm 0.64$ & $2.47 \pm 0.71$ & $\begin{array}{c}0.013 \\
t=2.561\end{array}$ \\
\hline FEV 1\% & $86.13 \pm 20.41$ & $68.77 \pm 11.03$ & $\begin{array}{c}<0.001 \\
\mathrm{Z}=4.380\end{array}$ \\
\hline $\begin{array}{c}\text { Peak } \\
\text { Expiratory } \\
\text { Flow Rate } \\
\text { (PEFR) } \\
\end{array}$ & $462.77 \pm 101.43$ & $380.87 \pm 121.89$ & 0.006 \\
\hline
\end{tabular}


The $\mathrm{p}$ value of MVV was found to be highly significant indicating marked diminution of MVV in study group as compared to the control. The $\mathrm{p}$ value of FEV1 was observed to be mildly significant showing mild decrease in FEV1 in study group. The $\mathrm{p}$ value of FEV $1 \%$ was of very high significance indicating a marked decrease in FEV 1\% in the study group. The $p$ value of PEFR is highly significant showing marked diminution of PEFR in the study group.

\section{DISCUSSION}

In the present study lung functions like FEV1, PEFR and MVV were estimated in patients of allergic rhinitis. They were compared with attenders and technicians of KVG Medical College and Hospital staff forming the control group.

The purpose of the current study was to re-evaluate the issue, whether allergic rhinitis led to a precocious or accelerated loss of pulmonary function as stated in several articles.

PFT parameters (MVV, FEV1, FEV 1\%, PEFR) were significantly reduced among patients of allergic rhinitis as seen in the previous studies. $(5,6,7,8)$

Anthropometric parameters did not show any significant change among the two groups. The cardiovascular parameters like pulse rate, blood pressure and respiratory rate were not different between the two groups.

\section{FEV1}

It was found that patients of allergic rhinitis showed reduced FEV 1\% as compared to normal subjects. A reduction of lung volumes in smaller airways was demonstrated in these patients. Giorgio C and Colleagues in their study demonstrated a statistically significant decrease in FEV1 and FEV 1\% among patients of perennial allergic rhinitis ( $p<0.001)$. (5) Gian LM et al in their study pointed that FEV1 and FEV 1\% decreased by upto $25 \%$ in patients of allergic rhinitis and also pointed that this can be an early marker of small airways impairment in subjects of allergic rhinitis.(6) Giorgio $\mathrm{C}$ and Colleagues in another study on patients of seasonal allergic rhinitis demonstrated a statistically significant decrease in FEV1 and FEV 1\% (p <0.001).(7)

In our study, FEV $1 \%$ has reduced to $68.77 \%$ compared to control $86.13 \%$ and FEV1, 2.47L in workers and $2.92 \mathrm{~L}$ among controls, indicating obstructive lung changes.

Similar to the previous studies, our study on comparison of following parameter MVV, FEV1, FEV 1\% and PEFR between the groups showed a significant reduction.

\section{PEFR}

It was observed that in patients of allergic rhinitis, PEFR shows a shift towards a lower mean value of the parameter.

Giorgio $\mathrm{C}$ and Colleagues in their study demonstrated a statistically significant decrease in PEFR among patients of perennial allergic rhinitis ( $p<0.001)$.(5) Giorgio $C$ and Colleagues in another study on patients of seasonal allergic rhinitis demonstrated a statistically significant decrease in PEFR $(\mathrm{p}<0.001)$. ${ }^{(6)}$

In our study, PEFR has reduced to 380.87 litres per minute among patients of allergic rhinitis compared to 462.77 litres per minute in the controls. This again probably indicates obstructive lung changes.

\section{MVV}

In our study, MVV in the workers has drastically reduced indicating changes like emphysema or airway obstruction, probably through immunological mechanism or poor respiratory muscle strength.

In a study by Giorgio $\mathrm{C}$ and Co-workers demonstrated a statistically significant decrease in MVV among patients of perennial allergic rhinitis ( $p<0.001) .{ }^{5}$ Gian LM et al also in their study showed significant increase in MVV in patient of early allergic rhinitis.(5)

Giorgio C and Colleagues in another study on patients of seasonal allergic rhinitis reported a statistically significant decrease in MVV ( $p<0.001) .{ }^{7}$ G Ciprandi and Co-workers in a study also reported statistically significant increase in MVV.(7)

\section{CONCLUSION}

Our study measured changes in pulmonary function using PFT in patients of allergic rhinitis in Sullia observed that pulmonary function test parameters like FEV1, FEV 1\%, PEFR and MVV showed a definite and significant decrease in patients compared to controls. Pulmonary function test parameters are decreased in patients of allergic rhinitis.

\section{LIMITATIONS OF THE STUDY}

The limitations of the present study were less number of the subjects.

\section{ACKNOWLEDGEMENTS}

We sincerely thank attenders and technicians of the KVG Medical College and Hospital staff, Sullia, for participating in the study.

\section{REFERENCES}

1. Aaron SD, Dales RE, Cardinal P. How accurate is spirometry at predicting restrictive pulmonary impairment? Chest 1999;115(3):869-73.

2. Ng ML, Warlow RS, Chrishanthan N, et al. Preliminary criteria for the definition of allergic rhiniris: a systemic evaluation of clinical parameters in a disease cohort (1). Clin Exp Allergy 2000;30(9):1314-31.

3. Settipane RA. Demographics and epidemiology of allergic and non allergic rhinitis. Allergy Asthma Proc 2001;22(4): 185-9.

4. Crapo RO. Pulmonary function testing. N Engl J Med 1994;331(1):25-30.

5. Ciprandi G, Cirillo I, Tosca MA, et al. Bronchial hyperreactivity and spirometric impairment in paitients with perennial allergic rhinitis. Int Arch Allergy Immunol 2004;133(1):14-8.

6. Marseglia GL, Cirillo I, Vizzaccaro A, et al. Role of forced expiratory flow at $25-75 \%$ as an early marker of small airways impairment in subjects with allergic rhinitis. Allergy Asthma Proc 2007;28(1):74-8.

7. Ciprandi G, Cirillo I, Tosca MA, et al. Bronchial hyperreactivity and spirometric impairment in paitients with seasonal allergic rhinitis. Respiratory Medicine 2004;98(9):826-31.

8. Ciprandi G, Cirillo I, Pistorio A. Impact of allergic rhinitis on asthma:effects on spirometric parameters. Allergy 2008;63(3):255-60. 